\title{
Average Concentration from T1 to T2 Normalized by Weight
}

National Cancer Institute

\section{Source}

National Cancer Institute. Average Concentration from T1 to T2 Normalized by Weight. NCI Thesaurus. Code C132443.

The area under the curve over the interval from T1 to T2 divided by the leng th of the interval and then divided by the weight. (CDISC) 